\title{
DETECCIÓN AUTOMÁTICA DE DIFERENCIAS ENTRE IMÁGENES PARA ESTIMACIÓN DE LA IRRITACIÓN DE PRODUCTOS MEDIANTE HET-CAM
}

\author{
Ignacio Pérez Muñoz \\ Universitat Politècnica de València, igpremuo@inf.upv.es \\ Antonio José Sánchez Salmerón \\ Universitat Politècnica de València, asanchez@isa.upv.es
}

\begin{abstract}
Resumen
HET-CAM es una técnica in vitro utilizada para realizar una estimación de la irritación ocular que produciría cualquier sustancia química, o mezcla de ellas, en el ojo (mucosas) humano. Esta técni$c a$, se basa en el análisis manual de los cambios producidos en las venas en distintos instantes de tiempo tras la aplicación de un producto sobre la membrana de un huevo fecundado. Dicho análisis se lleva a cabo por un experto que debe revisar y apuntar durante un periodo determinado de tiempo los cambios que hayan ocurrido. Con el fin de automatizar este proceso, en este trabajo se propone una primera aproximación a la detección automática de los cambios en la distribución de la sangre producidos en el huevo. En concreto, se proponen técnicas de procesado y segmentación de las imágenes que facilitan el proceso de monitorización realizado por los expertos.
\end{abstract}

Palabras clave: HET-CAM, procesamiento de imágenes, segmentación

\section{INTRODUCCIÓN}

El desarrollo de nuevos productos requiere realizar una valoración de su potencial irritante, para determinar las precauciones de uso de estos productos por parte de los consumidores. Dicha irritación se calcula mediante un índice, el cual indica su potencial irritante para las mucosas en los usuarios finales.

La obtención de los niveles de irritación y toxicidad de ciertos productos se suele realizar mediante experimentos sobre animales, como las pruebas de Draize [4]. Estos experimentos permiten obtener los niveles de irritación cutáneo y ocular [10] utilizando conejos albinos. Debido a la política de reducción de ensayos con animales promovida por la comisión europea, surge la necesidad de utilizar otras técnicas in vitro para valorar la irritación, el
HET-CAM surge como una alternativa a las pruebas de irritación ocular del test de Draize.

HET-CAM [7] es una técnica que consiste en la inspección de los cambios producidos en las venas de la membrana de huevos fecundados durante un tiempo determinado.

Para realizar el análisis mediante HET-CAM se utilizan huevos fecundados de gallinas Leghorn con una incubación de 10 días. Antes de aplicar el producto se elimina una pequeña parte de la cáscara en la parte superior del huevo, por donde se realiza el intercambio gaseoso y se elimina la primera membrana blanquecina, dejando así la membrana corioalantoidea al descubierto. Además, para poder visualizar las venas más fácilmente, se instala una iluminación sobre la membrana. Posteriormente se aplican $0.3 \mathrm{ml}$ del producto a analizar sobre la membrana. A partir de ese momento un experto supervisa el huevo durante 5 minutos para apuntar los instantes en los que se producen los cambios. Cuando se detecta un evento se apunta el tipo de evento y el instante en el que se ha producido, para poder posteriormente aplicar la fórmula del cálculo del índice de irritación.

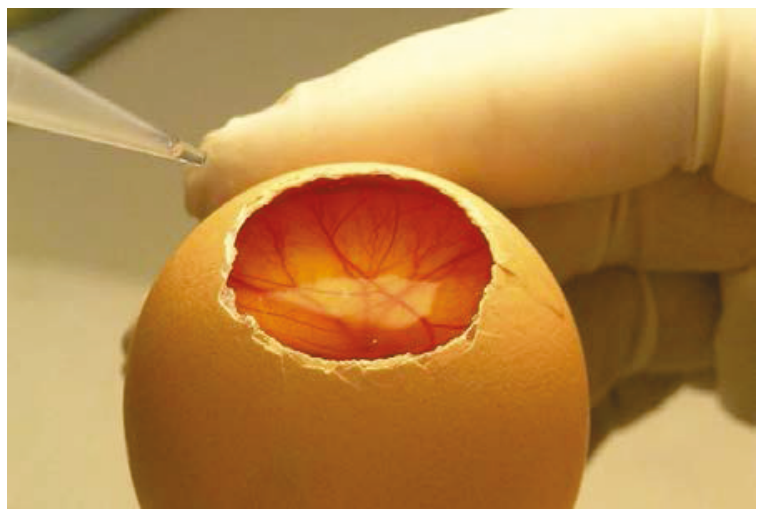

Figura 1: Huevo con la membrana corioalantoidea al descubierto [6].

Este trabajo supone una primera aproximación para llegar a realizar la detección automática de 
los eventos. Se proponen una serie de técnicas que permiten determinar si en un experimento se ha producido o no un evento, para de este modo, poder más adelante intentar detectar en qué instantes se han producido y el tipo del evento.

Existen trabajos donde se intenta automatizar el nivel de irritación producida por sustancias o mezclas, pero están basados en la monitorización, mediante sensores, del estado de las células sobre las que se aplica el producto [5]. Este trabajo, sin embargo, supone un primer paso a la detección del índice de irritación mediante visión por computador.

\subsection{TIPOS DE EVENTOS}

$\mathrm{Al}$ aplicarse el producto sobre la membrana coroalantoidea del huevo se pueden apreciar cuatro tipos principales de eventos.

\section{Hiperemia}

El evento de hiperemia se produce al haber un aumento del tamaño de la sección de las venas y capilares. En algunos casos, el incremento del riego en una determinada zona produce el aumento de vasos sanguíneos que anteriormente no eran visibles, pareciendo que aparecen de la nada.

\section{Hemorragia}

La hemorragia se produce cuando las paredes de los vasos se rompen, haciendo que la sangre se escape y se esparza de forma homogénea, o formando pequeños puntos anexos a los vasos.

\section{Lisis}

Este evento se produce cuando se observa una disminución de la sección de las venas y capilares, llegando en algunos casos a verse como una desaparición de las mismas.

\section{Coagulación}

El indicador de que este evento ha tenido lugar es el color rojo de la sangre, que suele oscurecerse e incluso tornarse marrón oscuro, también cuando coagula el albumen produciendo una opacidad en la membrana.

\section{2. ÍNDICE DE IRRITACIÓN}

El índice de irritación $i s$ se calcula a través del primer instante donde se han producido los eventos de hiperemia $x$, hemorragia $h$, lisis $l$, y coagulación c.

$$
i s=\sum_{i=1}^{4} v_{i} \cdot\left(\frac{301-t_{i}}{300}\right)
$$

La Fórmula 1 muestra el cálculo del índice de irritación dado el conjunto de instantes $t=\{x, h, l, c\}$ y los valores establecidos $v=\{3,5,7,9\}$. Cuanto mayor es el índice de irritación is mayor es el nivel de toxicidad del cosmético, y por lo tanto produce una mayor reacción sobre las personas.

\section{MATERIALES Y MÉTODOS}

En un primer paso para poder automatizar la detección de los eventos, se ha añadido una cámara encargada de capturar imágenes de la membrana coroalantoidea. La cámara captura imágenes de forma periódica después de haber aplicado el producto, utilizando un intervalo preestablecido.

Se ha utilizado como herramienta de captura un mini ordenador Raspberry Pi, el cual tiene conectada una cámara que está diseñada expresamente para este equipo. Esta cámara tiene una resolución de 2592 x 1944 píxeles y obtiene imágenes en formato RGB. En la Figura 2 se puede ver un ejemplo de una imagen capturada mediante dicha cámara, donde pueden apreciarse las venas y capilares del huevo además de pequeñas partes de cáscara en las esquinas inferiores de la imagen.

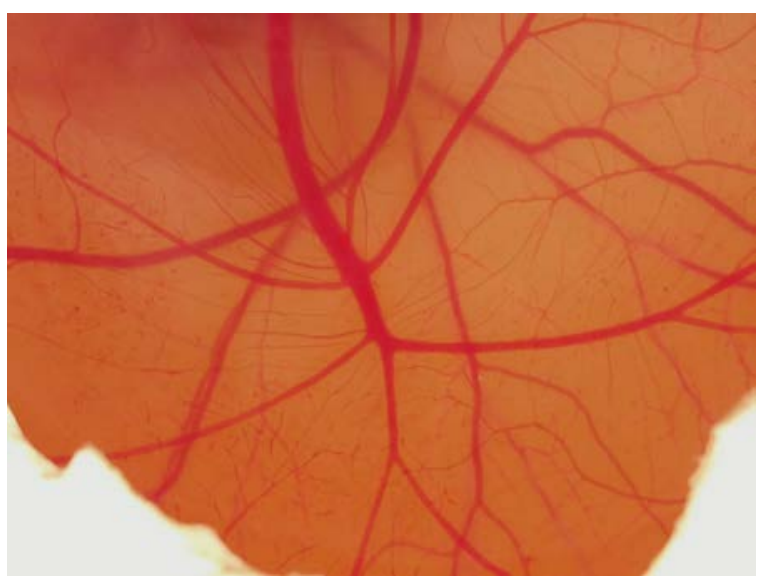

Figura 2: Imagen PATRÓN de la membrana del huevo.

El proceso de captura comienza con una primera imagen de la membrana sin producto, esta imagen se utiliza como referencia para poder posteriormente realizar la comparación con el resto de las imágenes. Esta primera imagen es etiquetada como PATRÓN. Después de aplicar el producto se toman un total de 31 imágenes con un intervalo de 10 segundos, dando como resultado una secuencia 
de imágenes de los primeros 5 minutos tras haber aplicado el producto. Las imágenes obtenidas son etiquetadas según el instante de tiempo en el que son tomadas, para poder obtener más tarde el instante en el que se producen los eventos.

Existen trabajos $[8,9]$ donde se realiza la extracción de venas con muy buenos resultados, pero tras probar estos métodos en las secuencias de imágenes se ha detectado que estos métodos no siempre resaltan la misma cantidad de venas en todas las imágenes, por lo que dificulta el trabajo a la hora de realizar comparaciones.

Con el fin de poder detectar más fácilmente si se ha producido algún tipo de evento, se han aplicado una serie de procedimientos que permiten resaltar y segmentar las venas y los capilares del resto de la imagen, garantizando en la mayor medida posible que las venas segmentadas en las distintas imágenes sean las mismas.

\subsection{EXTRACCIÓN DE LOS ÍNDICES DE LA IMAGEN}

La extracción de los índices de la imagen se realiza mediante la obtención de una imagen en escala de grises en la que se ha resaltado el color de las venas y los capilares.

En este tipo de imágenes donde se desea realizar una extracción de las venas se suele utilizar únicamente el canal verde, dado que comparado con los demás canales contiene una información más contrastada de las venas, tal y como puede verse en la Figura 3.

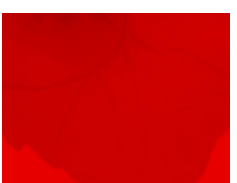

(a) Canal R

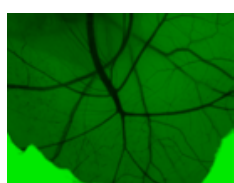

(b) Canal G

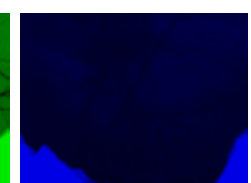

(c) Canal B
Figura 3: Canales RGB de la imagen por separado.

Se ha realizado un estudio comparativo de índices normalizados, previamente utilizados en otros trabajos [1, 3, 2], para obtener una imagen de grises donde se resaltara el nivel de rojo frente al resto de colores. Después de probar distintas combinaciones de los canales RGB de la imagen, se ha decidido utilizar una combinación definida en la Fórmula 2.

En la Figura 4 se puede ver un ejemplo de la imagen de índices $I$ obtenida a partir de la imagen de la Figura 2. Estos índices se han obtenido a partir de la Fórmula 2, donde $I_{x}$ equivale a cada uno de los canales RGB de la imagen con $x \in\{R, G, B\}$.

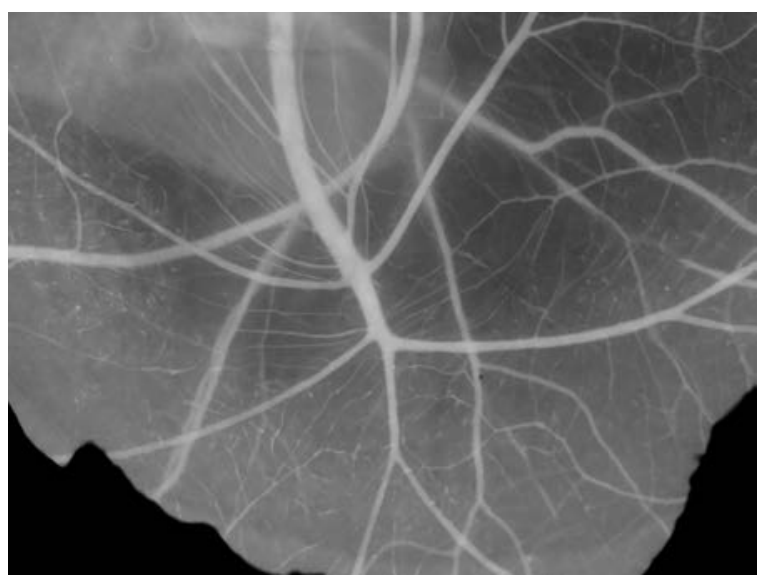

Figura 4: Imagen de índices de la imagen PATRÓN.

$$
I=2 \cdot G\left(I_{R}\right)-I_{G}-G\left(I_{B}\right)
$$

Además, en la Fórmula 2 también se utiliza un filtro gaussiano $G(x, y)$, el cual se aplica con un kernel de 21 x 21 y con $\sigma=5$. Debido a que el sensor de la cámara captura con una mayor resolución el canal verde, es necesario aplicar éste suavizado a los canales rojo y azul de la imagen, para evitar así una pérdida de resolución al realizar la combinación de colores.

\subsection{TRANSFORMACIÓN LOCAL}

Antes de realizar la segmentación de las venas se aplica una transformación local para realizar una corrección de las sombras.

Debido a que la transformación local aplicada resalta los valores oscuros sobre los claros, antes y después de aplicar la transformación local se realiza el complementario de la imagen de índices, de este modo, las venas resaltadas en blanco pasan a ser negras para después volver a pasar a ser blancas una vez normalizadas.

En la Figura 5 se puede ver un ejemplo del resultado obtenido tras aplicar las transformaciones locales a la imagen de la Figura 4.

La transformación local $\Gamma$ se aplica utilizando una ventana de tamaño $L$ centrada sobre el píxel $x$ de la imagen de índices $I$. En la Función 3, los valores $u_{\max }$ y $u_{\min }$ equivalen a los valores máximo y mínimo que se desean obtener, en este caso 255 y 0 respectivamente; y los valores $t_{\max } \mathrm{y} t_{\min }$ se corresponden con los valores máximo y mínimo de la imagen en escala de grises. El valor $\mu_{I}$ es el valor medio de todos píxeles de la imagen $I$, y el valor $r$ es utilizado para controlar el incremento de contraste. 


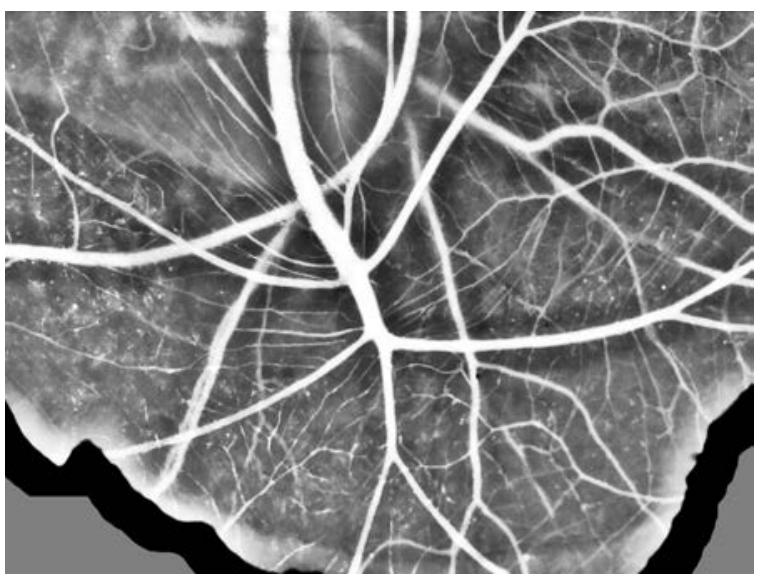

Figura 5: Imagen de índices después de haber aplicado la transformación local.

$\Gamma(I)= \begin{cases}\frac{\frac{1}{2}\left(u_{\max }-u_{\min }\right)}{\left(\mu_{I}-t_{\min }\right)^{r}}\left(t-t_{\min }\right)^{r}+u_{\min } & \text { si } t \leq \mu_{I} \\ \frac{-\frac{1}{2}\left(u_{\max }-u_{\min }\right)}{\left(\mu_{I}-t_{\max }\right)^{r}}\left(t-t_{\max }\right)^{r}+u_{\max } & \text { si } t>\mu_{I}\end{cases}$

En este caso, los valores de $L$ y $r$ utilizados son $L=201$ y $r=4$.

Además de probar esta técnica de normalizado, también se han realizado pruebas aplicando una ecualización de histogramas sobre ventanas extraídas de la imagen. A pesar de que este proceso es mucho más rápido, los resultados obtenidos no mejoran al normalizado anteriormente nombrado, por lo que esta técnica por histogramas ha sido descartada.

\subsection{SEGMENTACIÓN DE VENAS}

El último paso para detectar si se producen diferencias entre las imágenes de la secuencia, consiste en la segmentación de las venas y capilares para poder realizar la comparación más fácilmente. Este proceso se realiza definiendo un umbral mediante el cual todo píxel cuyo valor de índice sea inferior a éste, su valor pasa directamente a valer 0 .

Para poder ver de una forma más visual la segmentación de las venas, se ha aplicado un mapeado de color a la imagen para que ésta aparezca en pseudocolor. El mapeado consiste en asignar un color a cada uno de los valores de grises. En este caso se ha utilizado el color azul para el valor 0 y rojo para el valor máximo 255. En la Figura 5 se puede ver el mapa de color aplicado.

Al aplicar el mapa de color de la Figura 6 sobre la imagen de la Figura 5 obtenemos la imagen a color de la Figura 7, donde se resaltan muy bien las venas del huevo sobre el resto de la imagen.

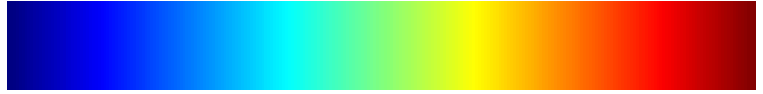

Figura 6: Mapa de color JET.

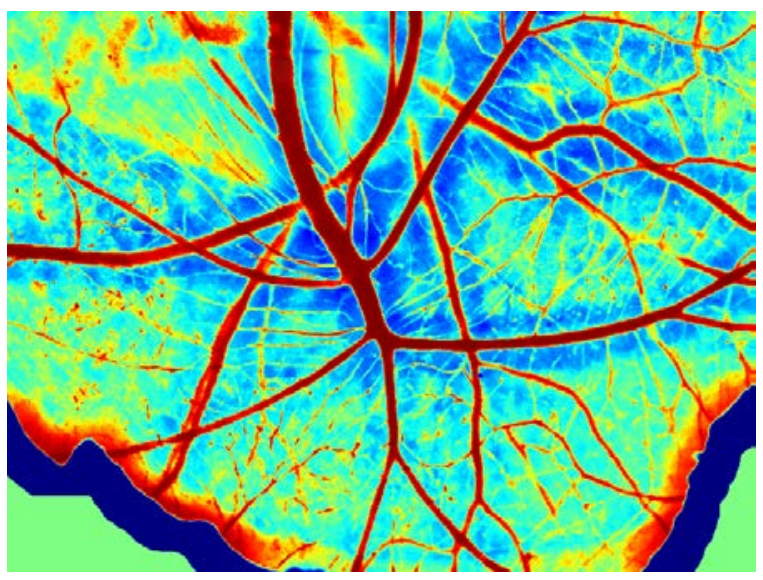

(3) Figura 7: Imagen de índices mostrada en pseudocolor.

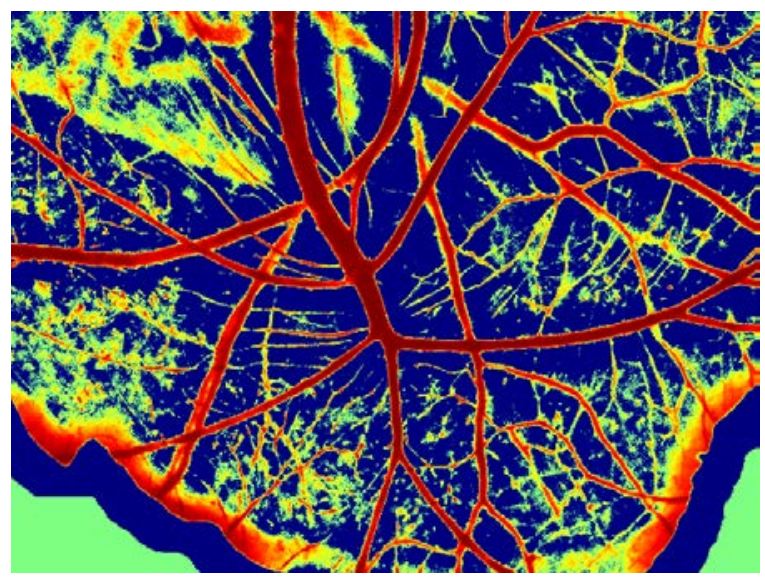

Figura 8: Peudocolor con un umbral de 120.

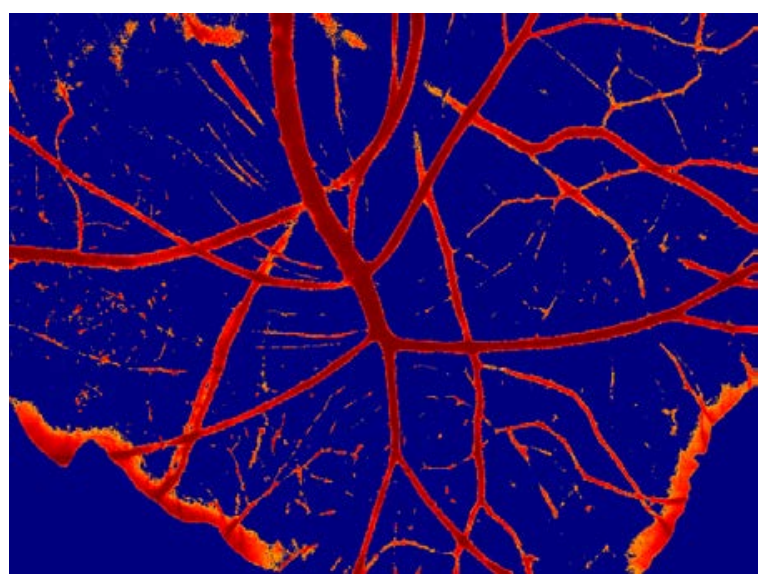

Figura 9: Peudocolor con un umbral de 180. 
En las Figuras 8 y 9 se observa el resultado obtenido tras aplicar un umbral de 120 y 180 respectivamente. Se aprecia como en la Figura 9 se han extraído la gran mayoría de las venas y capilares aislándolas del resto de la imagen.

\section{EXPERIMENTOS Y RESULTADOS}

Para poder detectar si en un experimento se ha producido algún evento se realiza una comparación de la cantidad de rojo producida entre diferentes imágenes. De este modo, si la cantidad de rojo en una imagen varía mucho con respecto a la primera quiere decir que ha sucedido algún evento. La detección del instante en el que se producen los cambios se lleva a cabo comparando la imagen del primer instante con los instantes siguientes, así se puede detectar cuando se produce un cambio significativo del nivel de rojo.

Se han realizado un total de 14 experimentos aplicando diferentes productos sobre huevos distintos, llegando a formar la suma de 448 imágenes. Tras aplicar el producto, muchas de las imágenes presentan burbujas o zonas con una visibilidad borrosa debido a la composición del producto. Estos efectos van desapareciendo con el paso del tiempo, llegando en la mayoría de las veces a desaparecer completamente. Además, en muchas ocasiones los huevos tienen pequeños trozos de cáscara que se desplazan con el movimiento del huevo. Todo esto dificulta la detección de los eventos debido a que pueden llegar a confundirse con un cambio en las venas.

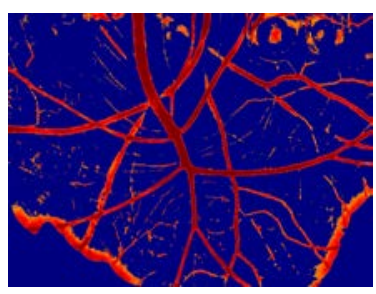

(a) Instante 0

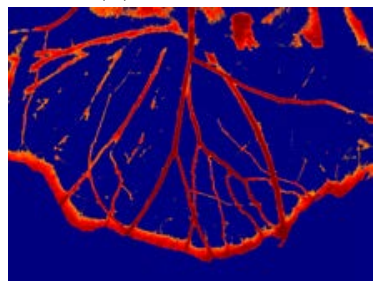

(c) Instante 0

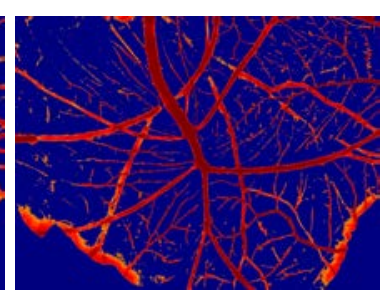

(b) Instante 300

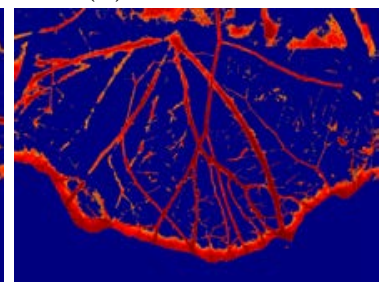

(d) Instante 300
Figura 10: Comparación de los índices del primer y último instante de dos experimentos con un umbral de 180 .

Se han realizado diversas pruebas comparando la imagen del primer instante (instante 0) con la imagen del último instante (instante 300) para poder, de este modo, comprobar si realmente se pueden llegar a apreciar las diferencias. En estas pruebas se ha comprobado que el hecho de que se produzca un evento queda perfectamente reflejado, y cómo la sensibilidad de detección varía en función del umbral utilizado para segmentar las venas. Dichas pruebas se han llevado a cabo de manera experimental, probando distintos umbrales y comprobando la cantidad de píxeles que quedan por encima de dicho umbral.

En las imágenes de la Figura 10 se aprecia como los cambios producidos en las venas entre el primer y último instante utilizando un umbral de 180 son claramente visibles, se puede detectar a simple vista que en las imágenes del último instante se produce un aumento de las venas sobre la membrana del huevo.

En la parte superior derecha de la imagen de la Figura 10a se pueden ver dos manchas esféricas producidas por burbujas creadas al aplicar el producto. Estas esferas desaparecen con el paso del tiempo y pueden inducir falsos positivos debido a que se confundan con cambios en las venas.

Variando el umbral en éstas imágenes se pueden llegar a evitar dichas burbujas, pero también se eliminan una gran cantidad de venas al realizar la segmentación como puede verse en las imágenes de la Figura 11, donde el umbral utilizado es de 230. A pesar de haber aumentado el umbral a un valor tan alto, aún se pueden detectar una gran cantidad de venas, y puede verse como todavía se detectan una gran cantidad de cambios entre ambas imágenes.

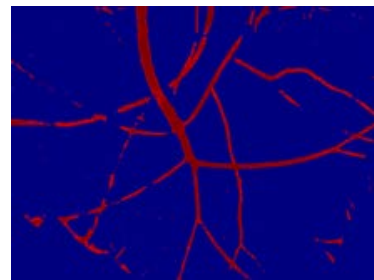

(a) Instante 0

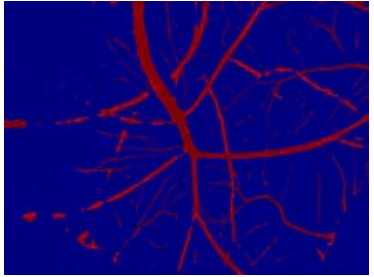

(b) Instante 300
Figura 11: Comparación de los índices con un umbral de 230 .

Una vez que se ha comprobado que la detección de los eventos queda reflejada con el nivel de rojo de las venas, el siguiente paso es comprobar si éstos también se pueden llegar a apreciar comparando la primera imagen con cualquier otro instante. De esta manera se puede llegar a obtener el instante en el que se producen los primeros eventos. En la Figura 12 se puede ver la comparativa de la imagen del primer instante junto con la imagen 
del instante 130, donde se aprecia que en este instante utilizando un umbral de 180 ya empiezan a aparecer diferencias entre ambas imágenes. En la Figura 12b se puede ver, además, como una de las burbujas del primer instante ya ha desaparecido.

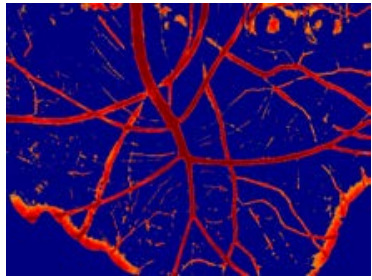

(a) Instante 0

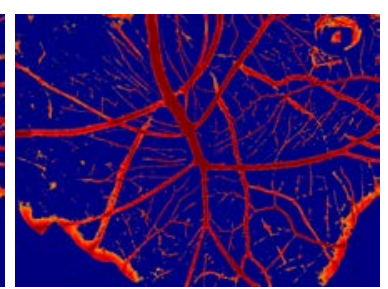

(b) Instante 130
Figura 12: Comparación de los índices del primer instante y el instante 130 con un umbral de 180 .

\section{CONCLUSIÓN}

Tras comprobar los resultados obtenidos por las pruebas realizadas, se puede concluir que la detección automática de diferencias entre las imágenes de un experimento puede realizarse comparando la imagen del primer instante con la de cualquier otro instante. El principal inconveniente es encontrar un umbral que satisfaga la mayor parte de los experimentos. Aunque con este método no es posible detectar el tipo de evento que se produce, sí permite detectar cuando se ha producido un cambio y segmentar las venas para poder, más adelante, clasificar el tipo de evento que se ha producido.

Para conseguir una mayor precisión, sería conveniente detectar los cambios que se producen debido al movimiento de las venas, las burbujas y manchas ocasionadas por el producto, y los pequeños trozos de cáscara. Estos cambios obstaculizan y dificultan la visualización de los eventos, además de generar confusión a la hora de realizar la comparativa.

Sería interesante abordar nuevas técnicas donde se trataran los problemas anteriormente citados, principalmente el movimiento de las venas, dado que éste supone el mayor problema. Es difícil de detectar si en una vena se ha producido cambio cuando ésta se ha desplazado a otra posición. Una posible solución es aplicar un registro no lineal para poder transformar las imágenes, y que de este modo las posiciones de las venas y capilares se correspondan entre distintos instantes.

Por otra parte, este trabajo no es más que un primer paso a la detección y clasificación de los eventos producidos por la irritación de sustancias químicas y mezclas. Este trabajo abre nuevas posibilidades en el campo del testeo de cualquier producto de consumo permitiendo automatizar la técnica de HET-CAM.

\section{Referencias}

[1] Benlloch, J. V., Agustí, M., Sanchez, A., \& Rodas, A. (1995, October). Colour segmentation techniques for detecting weed patches in cereal crops. In Proc. of Fourth Workshop on Robotics in Agriculture and the Food-Industry (pp. 30-31).

[2] Benlloch, J. V., Sánchez, A., Agustí, M., \& Albertos, P. (1996). Weed Detection in Cereal Fields Using Image Processing Techniques. Precision Agriculture, (precisionagricu3), 903-903.

[3] Benlloch, J. V., Sanchez, A., Christensen, S., \& Walger, M. (1996). Weed mapping in cereal crops using image analysis techniques. AgEng96, 2, 1059-1060.

[4] Draize, J. H., Woodard, G., \& Calvery, H. O. (1944). Methods for the study of irritation and toxicity of substances applied topically to the skin and mucous membranes. Journal of pharmacology and Experimental Therapeutics, 82(3), 377-390.

[5] Eggert, S., Alexander, F. A., \& Wiest, J. (2015, August). An automated microphysiological assay for toxicity evaluation. In Engineering in Medicine and Biology Society (EMBC), 2015 37th Annual International Conference of the IEEE (pp. 2175-2178). IEEE.

[6] Het Cam - Laboratorios Lim.s.a. [online] http://www.limsalab.com/servicios/ensayostoxicologicos/item/het-cam

[7] Luepke, N. P. \& Kemper, F. H. (1986). The HET-CAM test: an alternative to the Draize eye test. Food and Chemical Toxicology, 24(6), 495-496.

[8] Morales Martínez, S. (2015). Fundus characterization for automatic disease screening through retinal image processing (Doctoral dissertation).

[9] Walter, T., \& Klein, J. C. (2002, July). A computational approach to diagnosis of diabetic retinopathy. In Proceedings of the 6th Conference on Systemics, Cybernetics and Informatics (SCI2002) (pp. 521-526).

[10] Wilhelmus, K. R. (2001). The Draize eye test. Survey of ophthalmology, 45(6), 493-515. 